then to manage all others, as Dr. Marton suggests, at home. - B. Robert Meyer, MD, Richard A. Shlofmitz, MD, Bruce Hirsch, MD, Department of Medicine, North Shore University Hospital, Manhasset, New York

\section{Atrial Fibrillation, Stroke, and Anticoagulation}

To the Editors: - The review by Kitchens and Flegel ${ }^{1}$ is an important and well-researched overview of the vexing clinical problem of atrial fibrillation, stroke and anticoagulation. However, the degree of uncertainty noted in the discussion might have been reduced by considering the work done by Beck and Pauker on an analogous clinical problem, stroke in the setting of the tachycardia-bradycardia syndrome. ${ }^{2}$ Using a decision-analytic approach employing a Markov chain, Beck and Poruker were able to demonstrate that given the case of an 80-year-old woman with the tachy-brady syndrome, the decision to anticoagulate to prevent stroke was a very "robust" one. In a prior review, Wilson ${ }^{3}$ reached essentially the same conclusions as Kitchens and Flegel, and in addition, analyzed the difficulty of doing a randomized trial of anticoagulation for stroke prevention. Wilson reported that one would need to screen approximately 700,000 elderly persons to obtain a large enough population of persons with non-rheumatic atrial fibrillation who were available for treatment, assuming the relatively high risk of a type II error of $30 \%$. Further. Williams and Retchin as well as Zimmer and colleagues have pointed out the difficulties of conducting large clinical research studies in the elderly population. ${ }^{4.5}$ At this time, given the limited funds available for research, we may need to be satisfied with the uncertainty in the existing studies, coupled with our best efforts at careful analysis and review. - L. Gregory Pawlson, MD, MPH, Director, Center for Aging Studies and Services, The
George Washington University Medical Center, 1229 25th Street, NW, Washington, DC

\section{REFERENCES}

1. Kitchens JM. Flegel KM. Atrial fibrillation, stroke and anticoagulation: what is to be done? J Gen Intern Med 1986:1:126-9

2. Beck RJ, Pauker SG. Anticoagulation and atrial fibrillation in the bra dycardia-tachycardia syndrome. Med Decis Making 1981:1:285-301

3. Wilson DB. Chronic atrial fibrillation in the elderly: risk vs. benefits of long-term anticoagulation. I Am Geriatr Soc 1985;33:298-302

4. Williams ME. Retchin SM. Clinical geriatric research: still in adolescence J Am Geriatr Soc 1984:32:851-7

5. Zimmer AW, Caulkins E, Hadiey E, Ostfela AM, Kaye JM, Kaye D. Con ducting cinical research in geriatric populations. Ann Intern Med 1985;103. $276-83$

In reply: - We thank Dr. Pawlson for calling to our attention the article by Beck and Pauker. The Markov chain technique they used, varying sensitivity and with threshold analyses, is a useful tool that complements our review. From the Framingham studies it appears that the risk of embolic stroke in atrial fibrillation is higher the closer one is to the onset of atrial fibrillation. After four years, that risk has fallen and stabilized at $4 \%$ per year. A risk of $4 \%$ per year is well within the threshold limits favoring anticoagulation established by Beck and Pauker. Similarly, the probability of a catastrophic, anticoagulant-induced hemorrhage that would negate the decision to use anticoagulants is well beyond the risks published in any study of which we are aware. Dr. Powison correctly says that the uncertainty that he noted in our discussion could have been reduced by considering the work of Beck and Pauker.

We agree that $\alpha$ high priority should be given to research that might lead to safer means of stroke prevention. We would also encourage research that would help us separate those persons with atrial fibrillation who are likely to have an embolic event from those who will never have an embolus and in whom anticoagulation adds risk without benefit. - James M. Kitchens, MD, Kenneth M. Flegel, MD. Internal Medicine Unit, Royal Victoria Hospital, Montreal, Quebec H3AIAl, Conada 